\title{
Birdseed: A Potential Disease Problem for the Plantscape, Yard, and Garden?
}

\author{
A.E. Lighthiser ${ }^{1}$, S.G.P. Nameth ${ }^{2}$, and L.H. Rhodes ${ }^{2}$ \\ Department of Plant Pathology, The Ohio Agricultural Research and \\ Development Center, The Ohio State University, Columbus, OH 43210
}

Additional index words. perennial diseases, white mold disease

Bird feeding and bird watching are on the rise in the United States, and as a consequence many homeowners are planting naturalized areas in their yards to create an environment to attract birds and wildlife. The natural source of food and shelter provided by these areas is often supplemented with bird feeders to provide a year-round haven for a variety of birds. Black oil sunflower seed, Helianthus annuus L., is promoted as the top choice of seed for most wild birds and provides a high-quality protein and a high concentration oil source to their diet (Wild Birds Forever, 1999).

A recent observation into the contents of some commercial sunflower seed bags sold as feed for wild birds indicated the presence of the overwintering or resistant structures (sclerotia) of Sclerotinia sclerotiorum (Lib.) de Bary (Fig. 1). This pathogenic fungus produces a head rot (cottony rot) in commercial sunflowers that has a dramatic effect on the yield and oil components in the crop. Field surveys in eastern North Dakota in 1986 detected Sclerotinia head rot symptoms in $98 \%$ of the fields with $10.2 \%$ of the crop being affected (Gulya et al., 1989).

Sclerotinia sclerotiorum has a very wide host range and can cause disease in a variety of native plants, herbaceous perennials, annual

Received for publication 13 Apr. 2001. Accepted for publication 16 July 2001. Salaries and research support provided by State and Federal Funds appropriated to the Ohio Agricultural Research and Development Center, The Ohio State Univ.

${ }^{1}$ Academic Program Coordinator.

${ }^{2}$ Associate Professor. bedding plants, vegetables, and woody ornamentals (Farr et al., 1989). An infected sunflower can produce hundreds of sclerotia that can get into the harvested seed and eventually make their way to bird feeders. Birds will not eat the sclerotia but will discard them to the ground around the feeders. The sclerotia can lay dormant for months or years. Under the proper conditions, sclerotia will produce fruiting bodies that will produce plant-infecting spores or they can produce fungal hyphae that infect the host directly (Abawi and Grogan, 1979). The incidence of cottony rot in backyard flower, perennial, and vegetable gardens is on the increase (The C. Wayne Ellett Plant and Pest Diagnostic Clinic, 1997-2000). Therefore, a survey was initiated in an effort to determine the number of sclerotia found in a typical bag of commercial sunflower seed.

A representative one pound (453.6 g) sample of sunflower seed was scooped from 10 different bags of commercial sunflower seed purchased throughout the greater Columbus, Ohio, area. The contents of the scoop were spread out over a hard surface with a light background and the sclerotia were separated by hand and counted. Sclerotia collected from the sample were also weighed. To check the viability of the sclerotia in the infested seed, a random sample of sclerotia taken from each bag was surface sterilized and placed in the center of a petri dish containing potato dextrose agar and incubated at room temperature. After 1 week of incubation the plates were examined for the characteristic fungal growth.

The results of the survey are recorded in Table 1 . Of the 10 bags analyzed, five con- tained sclerotia of $S$. sclerotiorum. One bag contained $7.47 \mathrm{~g}$ of sclerotia in a 463.6-g sample or $1.7 \%$. Of the sclerotia tested, $100 \%$ were viable. There was a great amount of variation among brands and types of sunflower seed in quantity of sclerotia present.

This study indicates a potential plant disease problem associated with feeding sunflower seed in areas planted with bedding plants, herbaceous perennials, or vegetables. Management of Sclerotinia head rot is difficult since no resistant sunflower hybrid has been developed and no fungicides are registered in North Dakota for ascospore infection of sunflower (North Dakota State Univ. Extension, 2001). Proper rotation of crops, planting the least susceptible hybrids, and a rigid monitoring schedule are crucial to reducing disease in the field. After harvest, a double screen cleaning followed by cleaning on a gravity table can reduce the sclerotia of $S$. sclerotiorum to below $1 \%$. Considering the viability of sclerotia and the close to 400 species attacked by Sclerotinia sclerotiorum (North Dakota State Univ. Extension, 2001), the occurrence of any sclerotia in birdseed needs to be an issue that is seriously addressed by the sunflower industry.

\section{Literature Cited}

Abawi, G.S. and R.G. Grogan, 1979. Epidemiology of diseases caused by Sclerotinia species. Phytopathology 69:899-904.

Farr, D.F, G.F. Bills, G.P. Chamuris, and A.Y Rossman, 1989. Fungi on plants and plant products in the United States. APS Press, St. Paul, Minn.

Gulya, T.J., B.A. Vick, and B.D. Nelson. 1989. Sclerotinia head rot of sunflower in North Dakota: 1986 incidence, effect on yield and oil components, and sources of resistance. Plant Dis. 73:504-507.

North Dakota State Univ. Extension, 2001. Sunflower production-pest management-diseases. www.ext.nodak.edu/extpubs/plantsci/rowcrops/ eb25w-6e.html

Sample Records, 1997-2000. The C. Wayne Ellett Plant and Pest Diagnostic Clinic, The Ohio State Univ., Columbus.

Wild Birds Forever. 1999. The secret to wild bird feeding is black oil sunflower. www.birdsforever. com/blackoil.html.

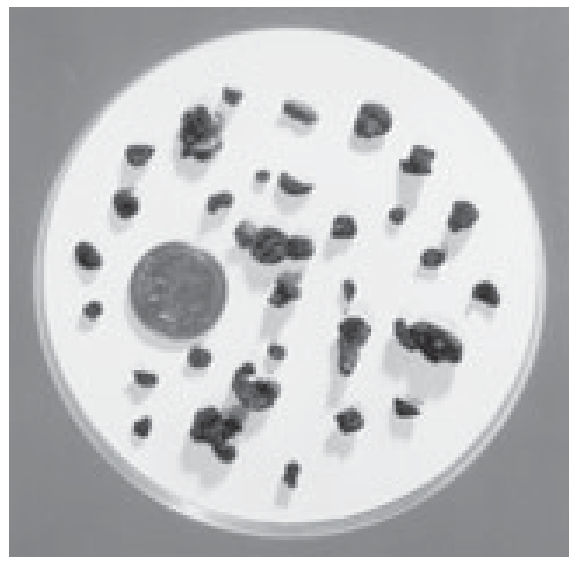

Table 1. Results of a commercial sunflower seed survey for sclerotia of S. sclerotiorum.

\begin{tabular}{|c|c|c|c|}
\hline Brand & $\begin{array}{l}\text { Sunflower seed } \\
\text { type \& bag wt }\end{array}$ & $\begin{array}{l}\text { Sclerotia } \\
\text { found }^{\mathrm{z}}\end{array}$ & $\begin{array}{c}\text { Date } \\
\text { purchased }\end{array}$ \\
\hline $\bar{A}$ & stripes, $11.340 \mathrm{~kg}$ & $27(0.913 \mathrm{~g})$ & 20 Mar. 2000 \\
\hline A & stripes, $11.340 \mathrm{~kg}$ & $6(0.320 \mathrm{~g})$ & 9 June 2000 \\
\hline A & stripes, $11.340 \mathrm{~kg}$ & $11(0.520 \mathrm{~g})$ & 1 Dec. 2000 \\
\hline B & bk oilly, $8.165 \mathrm{~kg}$ & None found & 1 May 2000 \\
\hline $\mathrm{C}$ & bk oil, $9.072 \mathrm{~kg}$ & None found & 1 May 2000 \\
\hline $\mathrm{D}$ & bk oil, $2.268 \mathrm{~kg}$ & $5(0.280 \mathrm{~g})$ & 9 June 2000 \\
\hline E & bk oil, $4.536 \mathrm{~kg}$ & None found & 2 May 2000 \\
\hline $\mathrm{F}$ & bk oil, $4.536 \mathrm{~kg}$ & None found & 2 May 2000 \\
\hline G & bk oil, $22.680 \mathrm{~kg}$ & $101(7.47 \mathrm{~g})$ & 25 Sept. 2000 \\
\hline G & bk oil, $22.680 \mathrm{~kg}$ & None found & 5 Jan. 2001 \\
\hline
\end{tabular}

Fig. 1. Typical sclerotia of S. sclerotiorum found in infested sunflower seed.

Note variation in size and shape. 